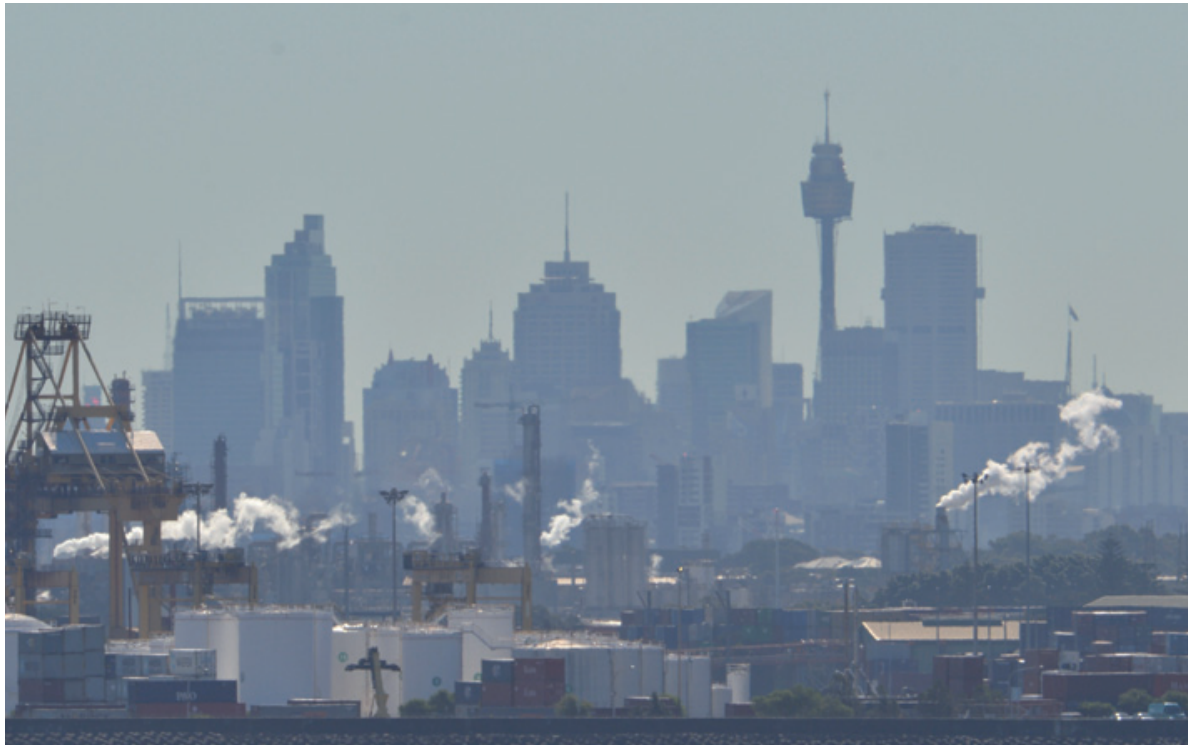

Emissions from the Australian energy sector fell by $5 \%$ after the introduction of a carbon tax.

POLICY

\title{
Anger as Australia dumps carbon tax
}

\section{Climate experts decry demise of emissions-control system.}

\section{BY QUIRIN SCHIERMEIER}

A ustralia's pioneering carbon-pricing mechanism has failed to survive its infancy. In a major victory for Prime Minister Tony Abbott, parliament agreed on 17 July to axe the scheme with immediate effect.

The repeal scraps both the unpopular carbon tax, established in July 2012, and proposals to turn it into a more flexible emissions-trading scheme in mid-2015. The initiative would have seen large companies and utility firms buying and selling emissions allowances in a joint market with the European Union (EU).

The move has disappointed many researchers. "This is a big setback for Australia's climate policy," says Frank Jotzo, a climate economist at the Australian National University in Canberra. "An economically sensible policy framework is being discarded and there is nothing adequate to replace it." He adds that it is unclear how Australia will meet its 2020 emissions-reduction target, "much less how the economy might be put on a trajectory to deeper cuts later on".

In its first year, the carbon tax raised Aus $\$ 6.6$ billion (US $\$ 6.2$ billion) from the almost 350 high-polluting companies obliged to pay about Aus $\$ 24$ for every tonne of carbon dioxide equivalent that they emitted. The tax, introduced by the previous government, led to a
$5 \%$ decrease in emissions from the power sector.

But critics say that the scheme has vastly increased consumer electricity prices. The government says that abolishing it - a key commitment in Abbott's 2013 election campaign - will reduce the cost of living by an average of Aus $\$ 550$ per household per year. After the scheme's demise, Abbott described it as a "useless, destructive tax".

Australia's total greenhouse-gas emissions -538.4 million tonnes of $\mathrm{CO}_{2}$ equivalent in 2013, down $0.8 \%$ from 2012 - account for less than $1.5 \%$ of total global emissions. But owing to extensive use of coal in electricity generation, the country is one of the world's largest polluters on a per capita basis.

The carbon-pricing mechanism was expected to reduce the nation's greenhouse-gas emissions by $5 \%$ below 2000 levels by 2020 . It will be replaced by an Emissions Reduction Fund that will aim to meet the same target by offering financial incentives for companies to increase their energy efficiency, and for landowners to replenish soil carbon and plant trees. But experts fear that the policy will be more costly and less effective than a market-based emissions-trading scheme.

"The carbon-pricing mechanism has been effective and the proposed alternative of a subsidy-based Emissions Reduction Fund has many holes," says Jotzo. "For Australia - as one of the richest, highest-emitting and most vulnerable countries to climate change - to repeal the backbone of its mitigation policy sends a negative signal internationally."

The status of other carbon-trading systems is mixed. The EU, which plans to cut its emissions by $40 \%$ below 1990 levels by 2030, is currently overhauling its trading scheme to reduce the number of emissions allowances available; the price of carbon has temporarily collapsed as a result of over-allocation of allowances during the recession. China is pushing forward with regional carbon-trading schemes, and the United States - which is reluctant to put a price on emissions - has announced plans to cut emissions from power plants by $30 \%$ from 2005 levels by 2030 . This will be achieved by improving efficiencies, shifting from coal power to gas and renewables, and implementing regional cap-and-trade emissions schemes.

The United Nations hopes to hammer out a binding international climate agreement by 2015 , based on national commitments. As part of this process, major economies including Australia are supposed to submit their post2020 emissions-reduction targets to the UN by April next year.

But Australia's U-turns on the carbon tax and other climate policies may discourage other nations from being as ambitious as they might have been, says Elliot Diringer, executive vice-president of the US Center for Climate and Energy Solutions in Arlington, Virginia. "Australia's decision underscores the vagaries of domestic policy-making," he says. "It saps rather than strengthens the global momentum - but it will not deter a global climate agreement in 2015."

The Australian Climate Change Authority (CCA), estab"Aneconomically lished by the sensible policy previous government framework is being discarded and there is nothing adequate to replace it." to provide advice on emissions targets, recommended in February that Australia's reduction goal should be $19 \%$ below 2000 levels by 2020 . The present government intends to close the CCA.

"The government's relatively weak and ineffective action on climate change is not consistent with a fair contribution from Australia towards global efforts to avoid dangerous climate change," says David Karoly, a climate scientist at the University of Melbourne and a member of the CCA.

Economists think that carbon pricing is the most efficient way to cut emissions. But Michael Grubb, who studies energy and climate policies at University College London, says that this often ignores the political reality - where decision-making tends to follow voters' immediate wishes and concerns. $\square$ SEE EDITORIAL P.383 